\section{Amplified Fragment Length Polymorphism Analysis of Genetic Diversity and Relationships of Wild and Cultivated Peach (Prunus persica L.)}

\author{
Fanjuan Meng and Mu Peng
}

College of Life Science, Northeast Forestry University, Harbin, 150040, China

\author{
Fachun Guan' \\ Department of Horticulture, Agricultural and Animal Husbandry College of \\ Tibet University, Tibet, Linzhi, 860000, China
}

Additional index words. Prunus mira, molecular marker, conservation, breeding

\begin{abstract}
To date, a narrow genetic base is a serious obstacle in peach (Prunus persica L.) production. Wild peach resources are useful germplasms for breeding new cultivars. In this study, amplified fragment length polymorphisms (AFLPs) were used to analyze the genetic diversity and relationships of wild and cultivated peach germplasms. These results showed that AFLP is an efficient technique for identifying the genetic relationships of wild and cultivated peach. Thirteen AFLP primer combinations generated a total of 377 scorable and clear fragments, all of which $(\mathbf{1 0 0 \% )}$ were polymorphic. Moreover, the polymorphism information content (PIC) values ranged from 0.91 to 0.96 with a mean of 0.95 . The results of the principal component analysis (PCoA) largely corresponded to those obtained using cluster analysis. The three principal axes accounted for $2.6 \%, 5.79 \%$, and $25.26 \%$ of the total variation, respectively. In conclusion, wild peach germplasms should receive special attention to ensure their conservation.
\end{abstract}

Peach (Prunus persica L.) is native to China and has been cultivated in China for the past 4000 to 5000 years (Ahmad et al., 2011; Maynard, 2008; Thacker, 1985). The homogeneity of peach recently resulted in the erosion of genetic diversity. In fact, the main commercial varieties represent a narrow genetic diversity, and there is concern that the narrow genetic base of the commercial varieties is a serious obstacle to improving peach production. Wild peach germplasms are useful in the control of disease and fruit quality and yield (Staudt et al., 2010; Wang, 1984). In addition, wild peach germplasms have been found to contain traits associated with tolerance to cold, drought, and high temperature and resistance to root-knot nematode (Meloidogyne incognita), aphids (Myzus persicae), and crown gall (Agrobacterium tumefaciens) (Tsipouridis and Thomidis, 2005; Wang et al., 2002). Thus, these diverse resources provide useful alleles to the cultivated peach gene pool, which is indispensable

Received for publication 16 Oct. 2014. Accepted for publication 31 Oct. 2014.

This work was supported by the Fundamental Research Funds for the Central Universities (DL13EA08-02; DL11CA02) and the National Natural Science Foundation of China (No. 31160386; 31170568).

${ }^{1}$ To whom reprint requests should be addressed; e-mailmfj19751@163.com.
This study provides beneficial information for cultivated peach breeding.

\section{Materials and Methods}

Plant materials. A total of 77 peach germplasms, including $54 \mathrm{P}$. mira Koehne ex Sargent from the Tibetan Plateau and 23 peach materials from Zhengzhou Fruit Research Institute (Zhengzhou, China), were examined (Table 1; Fig. 1).

DNA extraction. The total genomic DNA was extracted using the modified CTAB method as described by Bouhadida et al. (2011). The DNA concentration and quality were estimated using a ultraviolet-VIS spectrophotometer (ultraviolet-1800; Shimadzu Corporation) and $0.8 \%$ agarose gel electrophoresis. The extracted DNA was then stored at $-80{ }^{\circ} \mathrm{C}$ for polymerase chain reaction (PCR) amplification.

PCR amplification. The AFLP reactions were performed according to the method described by Vos et al. (1995) with some modifications. All of the primers and adapters are listed in Table 2. The DNA (150 ng) was digested with $5 \mathrm{U}$ of EcoRI and $5 \mathrm{U}$ of MseI (Promega, Madison, WI) in a total volume of $40 \mu \mathrm{L}$ at $37^{\circ} \mathrm{C}$ for $3 \mathrm{~h}$ and then incubated at $75^{\circ} \mathrm{C}$ for $15 \mathrm{~min}$. The digested DNA products were then ligated with $1 \mu \mathrm{L}$ of EcoRI adapter $(50 \mu \mathrm{M})$ and $1 \mu \mathrm{L}$ of MseI adapter $(5 \mu \mathrm{M})$ at $16{ }^{\circ} \mathrm{C}$ for $16 \mathrm{~h}$. After ligation, the mixture was diluted 10 -fold with $\mathrm{ddH}_{2} \mathrm{O}$. The pre-amplified reaction was performed using pre-selective primers. The pre-amplified mixture consisted of $5 \mu \mathrm{L}$ diluted solution, $10 \times$ PCR buffer, $2 \mathrm{~mm}$ dNTPs, $20 \mathrm{~mm} \mathrm{MgCl}_{2}$, $20 \mathrm{~mm}$ pre-amplification primer, and $1 \mathrm{U}$ of Taq DNA polymerase in a $20-\mu \mathrm{L}$ volume. The pre-amplified reaction was performed under the following conditions: denaturation at $94{ }^{\circ} \mathrm{C}$ for $3 \mathrm{~min}, 30$ cycles of $94{ }^{\circ} \mathrm{C}$ for $30 \mathrm{~s}$, $56^{\circ} \mathrm{C}$ for $30 \mathrm{~s}$, and $72{ }^{\circ} \mathrm{C}$ for $1 \mathrm{~min}$ and a final extension at $72{ }^{\circ} \mathrm{C}$ for $5 \mathrm{~min}$. The amplified products were diluted 30 -fold with $\mathrm{ddH}_{2} \mathrm{O}$ and used as the template for selective amplification. The selective amplification reactions were performed in a $20-\mu \mathrm{L}$ volume containing $5 \mu \mathrm{L}$ of template, $10 \times$ PCR buffer, $2 \mathrm{~mm}$ dNTPs, $25 \mathrm{~mm} \mathrm{MgCl}_{2}, 20 \mathrm{~mm}$ selective amplification primer, and $1 \mathrm{U}$ of Taq DNA polymerase. The PCR selective amplification was performed as follows: initial denaturation at $94^{\circ} \mathrm{C}$ for $3 \mathrm{~min}, 13$ cycles of $94^{\circ} \mathrm{C}$ for $30 \mathrm{~s}$, $65{ }^{\circ} \mathrm{C}$ for $30 \mathrm{~s}\left(-0.7{ }^{\circ} \mathrm{C}\right.$ at each cycle $)$ and $72{ }^{\circ} \mathrm{C}$ for $1 \mathrm{~min}, 23$ cycles of $94^{\circ} \mathrm{C}$ for $30 \mathrm{~s}$, $56^{\circ} \mathrm{C}$ for $30 \mathrm{~s}$, and $72^{\circ} \mathrm{C}$ for $1 \mathrm{~min}$, and a final step at $72{ }^{\circ} \mathrm{C}$ for $5 \mathrm{~min}$. The PCR products were separated on a $6 \%$ polyacrylamide gel for $2.5 \mathrm{~h}$ at $80 \mathrm{~W}$ and detected using silver staining as previously described by Bassam et al. (1991).

Data analysis. Only reproducible, clear, and well-resolved AFLP fragments were scored as the presence (1) or absence $(0)$ for each primer pair. The genetic parameters, including the total number of fragments, number of polymorphic fragments, and percentage of polymorphic fragments $(\%)$, were 
Table 1. List and description of 77 individuals used in this study.

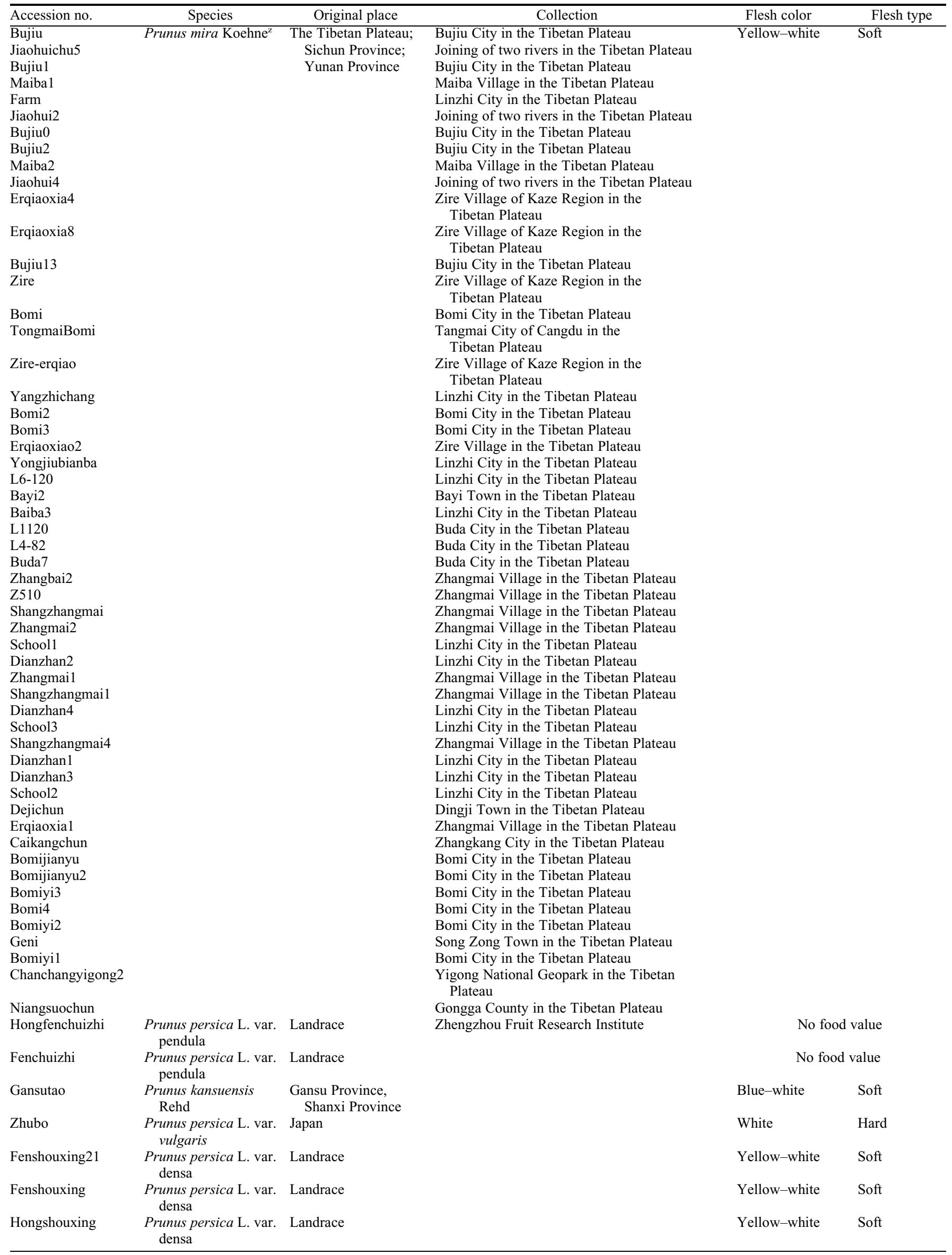


Table 1. (Continued) List and description of 77 individuals used in this study.

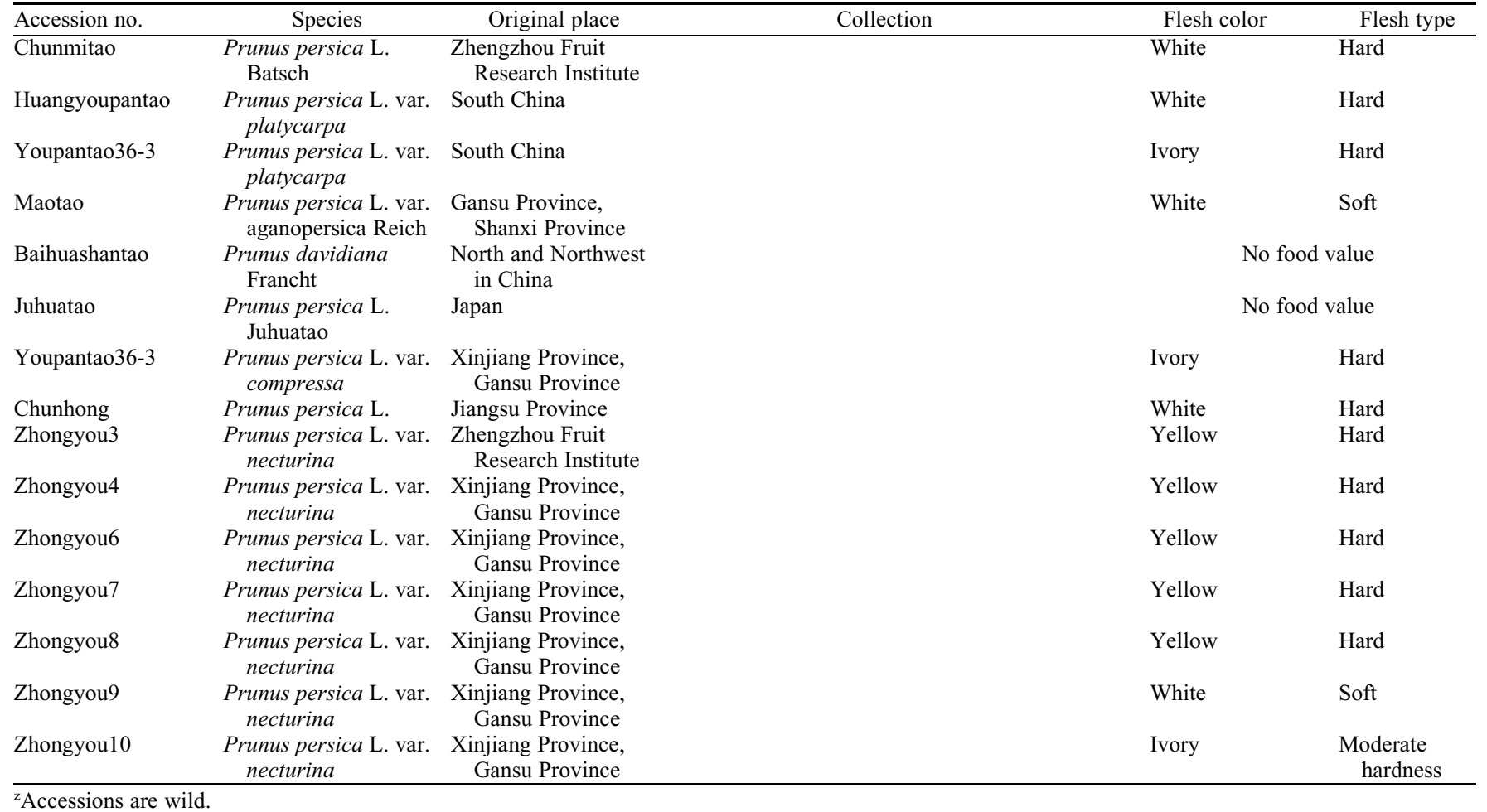

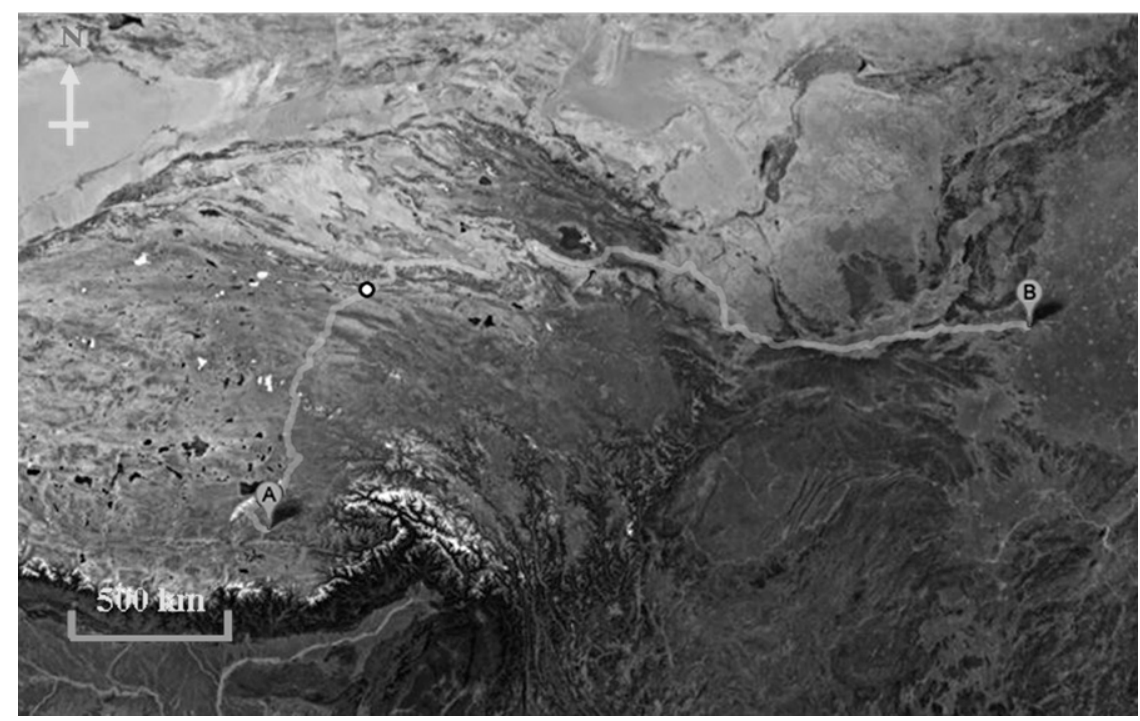

Fig. 1. Geographic sampling sites. (A) Tibetan Plateau; (B) Henan Province (Zhengzhou Fruit Research Institute).

estimated. A dendrogram corresponding to the similarity coefficient and PCoA results was constructed using NTSYS-pc software (Version 2.10) (Rohlf, 2000). The resolving power ( $\mathrm{Rp}$ ) was used to assess the power of the primers to discriminate all individuals (Prevost and Wilkinson, 1999). The assessment of $\mathrm{Rp}$ was performed using the Gilbert formula: $\mathrm{Rp}=\sum \mathrm{Ib}$, where $\mathrm{Ib}=1-[2 \times \mid 0.5$ $-P \mid]$ and $P$ is the frequency of the individuals containing the I band (Gilbert et al., 1999). In addition, the PIC was used to discriminate the ability of the primers. The formula was as follows:

$$
\mathrm{PIC}=1-\sum_{\mathrm{i}=1}^{\mathrm{k}} P_{\mathrm{i}}^{2}
$$

where $\mathrm{k}$ is the total number of alleles detected by a primer and $\mathrm{Pi}$ is the frequency of the allele in all individuals (Lynch and Ritland, 1999).

\section{Results}

AFLP polymorphism. Thirteen AFLP primer combinations generated a total of 377 scorable and clear fragments for 77 individuals, and all of these fragments $(100 \%)$ were polymorphic (Table 1; Fig. 2). The total number of fragments of each primer pair varied from 15 for $E c o$ RI-AC/MseI-AG to 42 for EcoRI-AG/MseI-AG with an average of 28.40. Moreover, the PIC values ranged from 0.91 to 0.96 with a mean of 0.95 (Table 2; Fig. 3). The mean of the Rp was 15.00 and ranged from 8.60 to 18.68 (Table 2).

Genetic diversity analysis. All 377 AFLP fragments scored were used for genetic diversity studies. A high level of similarity coefficients was observed. The average of the similarity coefficients values was 0.56 . The lowest similarity $(0.23)$ occurred between Dejichun and Dianzhan2 and the combination of Youpantao 36-3 and Zhongyou 10 showed the highest similarity (0.76) (data not shown).

Based on Nei's genetic distance, an unweighted pair group method with arithmetic average (UPGMA) dendrogram was constructed (Fig. 4). In the dendrogram, all of the materials were divided into three main groups at the similarity level of 0.31 (Fig. 3). Group I consisted of most of the materials from the Tibetan Plateau. Group II included some of the materials from the Tibetan Plateau and all of the individuals from the center of the peach resource. Only the Dejichun individual belonged to Group III. In addition, Group II contained two groups (Subgroups I and II). There were 10 individuals from the Tibetan Plateau in Subgroup I, and all of the materials from the Zhengzhou Fruit Research Institute were in Subgroup II.

PCoA analysis. The relationship among all of the individuals was also estimated using PCoA. The results of the PCoA analysis largely corresponded to those obtained using 
Table 2. Characteristics of the amplification products obtained using 13 amplified fragment length polymorphism primers.

\begin{tabular}{|c|c|c|c|c|c|c|}
\hline Primer pairs & Sequences $\left(5^{\prime}-3^{\prime}\right)$ & TNF & NPF & PP (\%) & $\mathrm{Rp}$ & $\mathrm{PIC}$ \\
\hline EcoRI-AA/MseI-AA & GAC TGC GTA CCA ATT C-AA/GAT GAG TCC TGA GTA A-AA & 32 & 32 & 100 & 16.36 & 0.96 \\
\hline EcoRI-AA/MseI-GT & GAC TGC GTA CCA ATT C-AA/GAT GAG TCC TGA GTA A-GT & 24 & 24 & 100 & 15.53 & 0.95 \\
\hline EcoRI-AC/MseI-AC & GAC TGC GTA CCA ATT C-AC/GAT GAG TCC TGA GTA A-AC & 34 & 34 & 100 & 12.16 & 0.95 \\
\hline EcoRI-AC/MseI-GT & GAC TGC GTA CCA ATT C-AC/GAT GAG TCC TGA GTA A-GT & 33 & 33 & 100 & 18.68 & 0.96 \\
\hline EcoRI-AG/MseI-AG & GAC TGC GTA CCA ATT C-AG/GAT GAG TCC TGA GTA A-AG & 42 & 42 & 100 & 16.91 & 0.96 \\
\hline EcoRI-AT/MseI-AT & GAC TGC GTA CCA ATT C-AT/GAT GAG TCC TGA GTA A-AT & 37 & 37 & 100 & 15.35 & 0.96 \\
\hline EcoRI-AT/MseI-GT & GAC TGC GTA CCA ATT C-AT/GAT GAG TCC TGA GTA A-GT & 25 & 25 & 100 & 13.82 & 0.94 \\
\hline EcoRI-CA/MseI-CA & GAC TGC GTA CCA ATT C-CA/GAT GAG TCC TGA GTA A-CA & 32 & 32 & 100 & 18.03 & 0.96 \\
\hline EcoRI-TA/MseI-AA & GAC TGC GTA CCA ATT C-TA/GAT GAG TCC TGA GTA A-AA & 26 & 26 & 100 & 23.12 & 0.96 \\
\hline Total & & 369 & 369 & - & 195 & - \\
\hline Average & & 28.40 & 28.40 & 100 & 15.00 & 0.95 \\
\hline
\end{tabular}

$\mathrm{TNF}=$ total number of fragments; NPF $=$ number of polymorphic fragments; PP $(\%)=$ percentage of polymorphic fragments; Rp $=$ resolving power; PIC $=$ polymorphic information content.

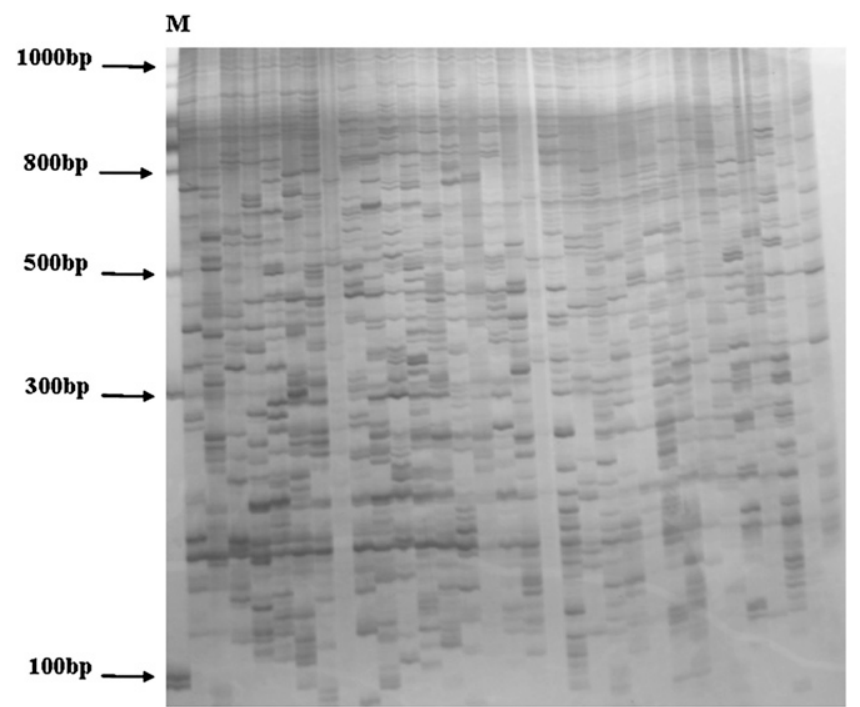

Fig. 2. Amplified fragment length polymorphism image of parts of individuals amplified using the primer combination E11-M41. M indicates the DNA marker ladder.

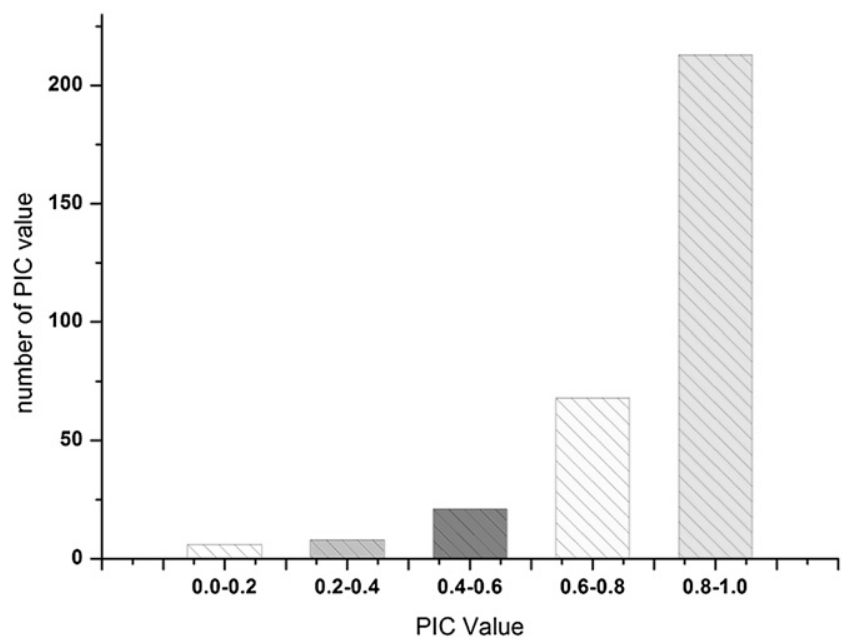

Fig. 3. Distribution of the polymorphism information content obtained using amplified fragment length polymorphism.

cluster analysis. The three principal axes accounted for $2.6 \%, 5.79 \%$, and $25.26 \%$ of the total variation, respectively. The first two axes separated all of the individuals into two groups. One group included all of the individuals from the center of the peach resource. The remaining individuals (from the Zhengzhou Fruit Research Institute) with the exception of Dejichun were clustered together to form one group (Fig. 5).

\section{Discussion}

AFLP polymorphism. AFLP has been extensively used in previous studies as a technique to detect molecular polymorphisms in cultivars and wild peach germplasms (Aranzana et al., 2003; Hu et al., 2005; Wang et al., 2008). Using AFLP, Wang et al. (2006) found a polymorphic percentage of $29.5 \%$ for nine primer combination pairs among 94 wild peach germplasms. Sixteen AFLP primer combinations produced a total of 837 fragments and 146 polymorphic bands with a polymorphism percentage of $17.5 \%$, as reported by $\mathrm{Xu}$ et al. (2006). These results suggested that a low level of genetic diversity is present among peach germplasms based on the AFLP technique. Compared with previous studies, high levels of polymorphism $(100 \%)$ were found in this study through the evaluation of the genetic diversity in Prunus mira ( $P$. mira Koehne ex Sargent) germplasms based on AFLP. This result suggested that $P$. mira and other peach species have a broad relationship. However, some potential reasons for these different levels of polymorphism may be correlated with the material size and the level of polymorphism of the primer combinations.

Although the AFLP technique may be useful for detecting genetic diversity in different peach germplasms, none of the results can be simply compared with those of other studies as a result of different genotypes and primer pairs. Thus, different marker techniques should be used to estimate DNA polymorphisms in peach germplasms (Testolin et al., 2000). For instance, Bouhadida et al. (2011) analyzed 94 peach cultivars using six simple sequence repeat (SSR) markers and found that SSR is very useful for future peach identification studies. Cao et al. (2012) detected highly polymorphic SSR markers among 104 peach landrace accessions using 53 SSR markers. Despite having a high variability for the identification of all peach cultivars, SSR was found to be relatively less variable compared with other species 


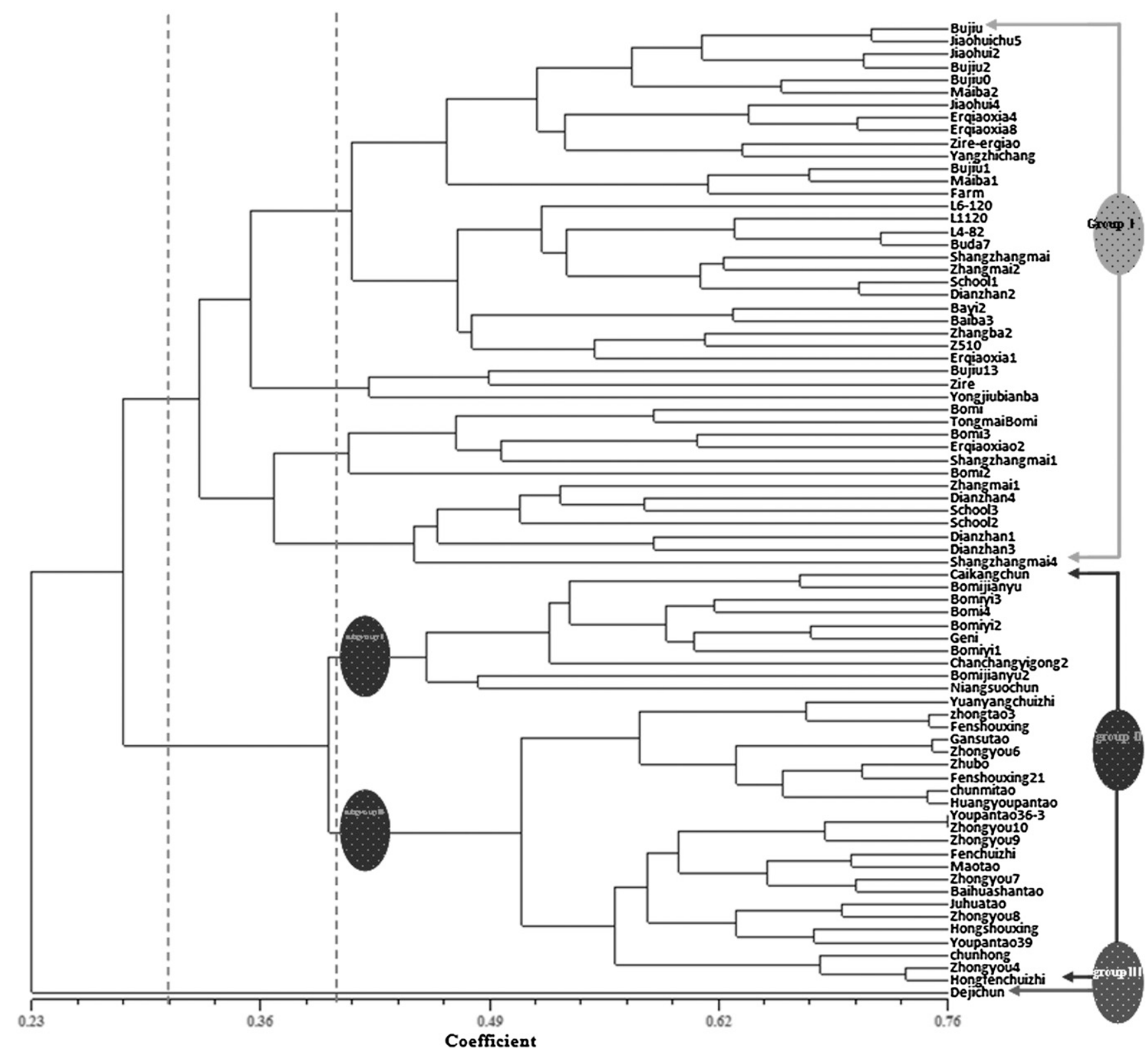

Fig. 4. Dendrogram of 77 individuals based on the data of amplified fragment length polymorphism using the unweighted pair group method with arithmetic average method. The genotype names are shown in Table 1.

(Aranzana et al., 2012). Thus, considering the limitation of different marker techniques, the combination of two or more molecular marker systems is most likely efficient for the conservation and management of peach germplasms. Furthermore, the effects of factors on morphological traits and fruit development should be taken into account when elucidating the genetic structure in peach germplasm resources (Cao et al., 2012).

Genetic diversity analysis. In China, peach, as a cultivated plant, has existed for thousands of years (Everett, 1982). As a selfpollinating plant, peach has very low genetic variation (Scorza et al., 1985). To enrich the genetic diversity of peach, we need to identify more wild peach resources. The rich genetic basis of wild peach germplasms is well known and has been demonstrated; however, the relationships among these germplasms remain unclear (Wang et al., 2008).

To date, peach is widely cultivated in China as an important fruit crop. In particular, many wild peach germplasms have attracted much attention as a result of their specific characteristics (Aradhya et al., 2004; Guan et al., 2014; Wang et al., 2006). This may be helpful for breeding peach cultivars with potentially new biotic and abiotic stresses (Cao et al., 2012). However, their genetic relationships are controversial and unclear. For example, Gansutao (P. kansuensis Rehd) and Prunus mira (P. mira Koehne ex Sargent) have a relatively close relationship, as reported by Zong and Duan (1987). However, this result was inconsistent with our findings. In the present study, Gansutao was clustered with Zhongyou6 ( $P$. persica var. necturina), which is consistent with the results obtained by $\mathrm{Yu}$ et al. (2004). In addition, Youpantao36-3 ( $P$. persica var. platycarpa) was closely clustered with Zhongyou10 $(P$. persica var. necturina), which is consistent with the findings reported by Cheng et al. (2001). In addition, Chunmitao (P. persica L. Batsch) and Huangpantao ( $P$. persica var. platycarpa) were clustered together in Subgroup I, most likely as a result of their evolutionary relationship (Cheng et al., 2001, 2002; Yang et al., 2001). It is common that Shouxingtao $(P$. persica var. densa) is derived from Maotao ( $P$. persica var. aganopersica Reich.) (Yang et al., 2001). However, Maotao was clustered not with Shouxingtao but with Fenchuizhi ( $P$. persica var. pendula). We hypothesized that Maotao may be closely related to Chuizhitao ( $P$. persica var. pendula). Guo et al. (1986) reported that 


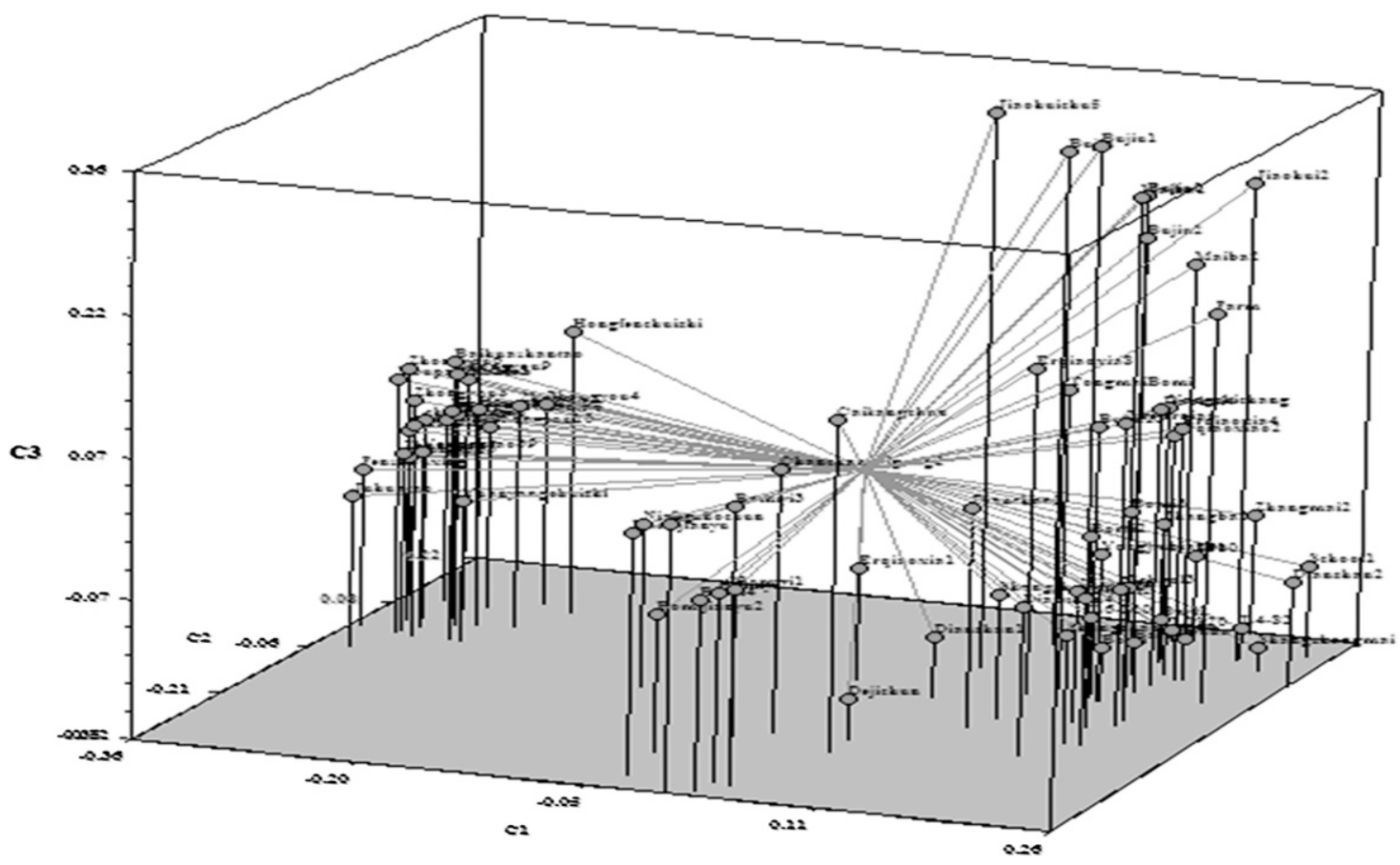

Fig. 5. Principal coordinate analysis of 77 individuals based on amplified fragment length polymorphism marker data.

a close relationship existed among Gansutao, Shantao ( $P$. davidiana Francht), and cultivated $P$. persica L., which is consistent with our findings.

The dendrogram showed that all of the individuals from the Zhengzhou Fruit Research Institute were localized in Group II, possibly as a result of the existence of a common genetic basis within this group. Moreover, the high genetic distances (data not shown) detected between these materials confirmed the higher diversity of individuals from the Zhengzhou Fruit Research Institute in this study. Importantly, the Zhengzhou Fruit Research Institute of the Chinese Academy of Agricultural Sciences, which was founded in 1960, is a national professional research organization of deciduous fruit that studies peach germplasms and develops new cultivars. Thus, we should enrich the peach gene pool to conserve them for the breeding of new varieties and to avoid genetic erosion.

In the present study, the relationship between $P$. mira and other peach germplasms was remote (Fig. 4). This finding indicated that $P$. mira demonstrates a genetic difference with other $P$. persica germplasms. Wang and Zhou (1990) confirmed that $P$. mira is the ancestor of cultivated peach. In addition, at the level of 0.31 , Dejichun formed a distinct group (Group III), indicating its clear differentiation from the other materials. This result is most likely because of the adaptation to a socioeconomic factor or geographical isolation. Indeed, the Tibetan Plateau is a unique geographic area with many geographic barriers such as the Tanggula Mountains, Lanchang River, Kunlun Mountains, and Nujiang River (Zhang and Jiang, 2006). Thus, many specific germplasms may be formed in the Tibetan Plateau.
Based on the genetic similarity matrices, the UPGMA dendrogram indicated that most of the individuals from Bomi City in the Tibetan Plateau were clustered to form one group (Subgroup I). This result indicated that most of the individuals belonging to the Bomi group had close genetic relationships. This low diversity may be the result of a selfmating system, environmental similarities, and a small population size, which would not facilitate genetic drift and cause a low level of genetic variation.

Conservation of wild peach germplasms. China is the native homeland of the peach tree and has abundant peach germplasms. However, the genetic narrowness of modern peach cultivars is a bottleneck to the breeding of new peach varieties. Wild peach germplasms have a high level of genetic diversity and are known to have many valuable genes that have not been used, e.g., resistance to disease and environmental stress (Cho et al., 2012; Sauge et al., 1998). However, there is an extremely dispersed distribution of wild peach germplasms. Moreover, some wild peach germplasms have been in danger of extinction as a result of human activities such as agriculture and pasture needs ( $\mathrm{Li}$ et al., 2013; Wang et al., 2010; Wu et al., 2003). Thus, these germplasms should receive special attention to ensure their conservation, which would necessitate a variety of conservation approaches depending on the specific biological factors. These approaches should include the conservation of ecosystems/agro-ecosystems, naturally occurring gene pools, and specific genetic stocks such as the tubers and roots used by communities (Altieri et al., 1987; Brush, 1991). Furthermore, more national research institutes have been founded as priority conservation sites, and areas where the wild peach germplasms are found within the protected areas should be demarcated to not allow any activity.

Overall, our results indicated that AFLP is a powerful and effective tool for the analysis of the genetic diversity of wild and cultivated peach germplasms. Furthermore, further analyses using several molecular markers are required to confirm our conclusions, and more potential peach germplasms should be collected for the breeding of new varieties.

\section{Literature Cited}

Ahmad, R., D.E. Parfitt, J. Fass, E. Ogundiwin, A. Dhingra, T.M. Gradziel, D. Lin, N.A. Joshi, P.J. Martinez-Garcia, and C.H. Crisosto. 2011. Whole genome sequencing of peach (Prunus persica L.) for SNP identification and selection. BMC Genomics 12:569.

Altieri, M.A., M. Anderson, and L.C. Merrick. 1987. Peasant agriculture and the conservation of crop and wild plant resources. Conserv. Biol. $1: 49-58$.

Aradhya, M.K., C. Weeks, and C.J. Simon. 2004 Molecular characterization of variability and relationships among seven cultivated and selected wild species of Prunus L. using amplified fragment length polymorphism. Sci. Hort. 103:131-144.

Aranzana, M.J., J. Carbó, and P. Arús. 2003. Using amplified fragment-length polymorphisms (AFLPs) to identify peach cultivars. J. Amer. Soc. Hort. Sci. 128:672-677.

Aranzana, M.J., E. Illa, W. Howad, and P. Arús 2012. A first insight into peach [Prunus persica (L.) Batsch] SNP variability. Tree Genet. Genomes 8:1359-1369.

Bassam, B.J., G. Caetano-Anollés, and P.M. Gresshoff. 1991. Fast and sensitive silver staining of DNA in polyacrylamide gels. Anal. Biochem. 196:80-83.

Bouhadida, M., M.Á. Moreno, M.J. Gonzalo, J.M. Alonso, and Y. Gogorcena. 2011. Genetic variability of introduced and local Spanish 
peach cultivars determined by SSR markers. Tree Genet. Genomes 7:257-270.

Brush, S.B. 1991. A farmer-based approach to conserving crop germplasm. Econ. Bot. 45:153-165.

Cao, K., L. Wang, G. Zhu, W. Fang, C. Chen, and J. Luo. 2012. Genetic diversity, linkage disequilibrium, and association mapping analyses of peach (Prunus persica) landraces in China. Tree Genet. Genomes 8:975-990.

Cheng, H.Y., W.C. Yang, and J.Y. Hsiao. 2001. Genetic diversity and relationship among peach cultivars based on random amplified microsatellite polymorphism (RAMP). Bot. Bull. Acad. Sin. 42:201-206.

Cheng, Z. and H. Huang. 2009. SSR fingerprinting Chinese peach cultivars and landraces (Prunus persica) and analysis of their genetic relationships. Sci. Hort. 120:188-193.

Cheng, Z.P., C.Z. Chen, Z.W. Chen, and X.X. Deng. 2002. Study on genetic diversity of Amygdalus persica based on RAPD markers. Journal of Wuhan Botanical Research 2:11.

Cho, K.H., E.Y. Nam, K.M. Bae, I.S. Shin, S.H. Kim, H.R. Kim, and K. Chung. 2012. Analysis of genetic diversity among wild peach germplasms using DNA markers. Korean Journal of Breeding Science 44:9.

Everett, T.H. 1982. The New York botanical garden illustrated encyclopedia of horticulture. Garland Publishing Inc., New York, NY.

Gilbert, J., R. Lewis, M. Wilkinson, and P. Caligari. 1999. Developing an appropriate strategy to assess genetic variability in plant germplasm collections. Theor. Appl. Genet. 98:1125-1131.

Guan, F., S. Wang, R. Li, M. Peng, and F. Meng. 2014. Genetic diversity of wild peach (Prunus mira Koehne kov et. kpst) from different altitudes in the Tibetan Plateau by pollen morphous and RAPD markers. HortScience 49:1017-1022.

Guo, Z., Z. Lv, G. Li, and Y. Mu. 1986. Karyotype analysis of P. davidiana francht and P. kansuensis reha. Journal Publishing Department of Agricultural University of Hebei 9:5.

$\mathrm{Hu}, \mathrm{D}$., Z. Zhang, D. Zhang, Q. Zhang, and J. Li. 2005. Genetic relationship of ornamental peach determined using AFLP markers. HortScience 40:1782-1786.

Kenis, K. and J. Keulemans. 2005. Genetic linkage maps of two apple cultivars (Malus $\times$ domestica Borkh.) based on AFLP and microsatellite markers. Mol. Breed. 15:205-219.

Li, X., X. Meng, H. Jia, M. Yu, R. Ma, L. Wang, K. Cao, Z. Shen, L. Niu, and J. Tian. 2013. Peach genetic resources: Diversity, population structure and linkage disequilibrium. BMC Genet. 14:84.

Lynch, M. and K. Ritland. 1999. Estimation of pairwise relatedness with molecular markers. Genetics 152:1753-1766.
Maynard, D.N. 2008. Underutilized and underexploited horticultural crops. HortScience 43: 279.

Mueller, U.G. and L.L. Wolfenbarger. 1999. AFLP genotyping and fingerprinting. Trends Ecol. Evol. 14:389-394.

Ouinsavi, C. and N. Sokpon. 2010. Morphological variation and ecological structure of Iroko (Milicia excelsa Welw. CC Berg) populations across different biogeographical zones in Benin. Intl. J. For. Res. 2010.

Pang, X.M., C.G. Hu, and X.X. Deng. 2007. Phylogenetic relationships within Citrus and its related genera as inferred from AFLP markers. Genet. Resources Crop Evol. 54: 429-436.

Prado, M., M. Herrera, R. Vázquez, S. Romo, and M. González. 2005. Micropropagation of two selected male kiwifruit and analysis of genetic variation with AFLP markers. HortScience 40:740-746.

Prevost, A. and M. Wilkinson. 1999. A new system of comparing PCR primers applied to ISSR fingerprinting of potato cultivars. Theor. Appl. Genet. 98:107-112.

Rohlf, F. 2000. NTSYS-PC, numerical taxonomy system for the PC Exeter software. Version 2.1. Applied Biostatistics Inc., Setauket, New York.

Sauge, M.H., J. Kervella, and T. Pascal. 1998. Settling behaviour and reproductive potential of the green peach aphid Myzus persicae on peach varieties and a related wild Prunus. Entomol. Exp. Appl. 89:233-242.

Scorza, R., S. Mehlenbacher, and G. Lightner. 1985. Inbreeding and coancestry of freestone peach cultivars of the eastern United States and implications for peach germplasm improvement. J. Amer. Soc. Hort. Sci. 110:404-409.

Staudt, M., B. Jackson, H. El-Aouni, B. Buatois, J.P. Lacroze, J.L. Poëssel, and M.H. Sauge. 2010. Volatile organic compound emissions induced by the aphid Myzus persicae differ among resistant and susceptible peach cultivars and a wild relative. Tree Physiol. 30:1320 1334.

Testolin, R., T. Marrazzo, G. Cipriani, R. Quarta, I. Verde, M.T. Dettori, M. Pancaldi, and S. Sansavini. 2000. Microsatellite DNA in peach (Prunus persica L. Batsch) and its use in fingerprinting and testing the genetic origin of cultivars. Genome 43:512-520.

Thacker, C. 1985. The history of gardens. Univ. of California Press, Oakland, CA.

Tsipouridis, C. and T. Thomidis. 2005. Effect of 14 peach rootstocks on the yield, fruit quality, mortality, girth expansion and resistance to frost damages of May Crest peach variety and their susceptibility on Phytophthora citrophthora. Sci. Hort. 103:421-428.
Vos, P., R. Hogers, M. Bleeker, M. Reijans, T. van De Lee, M. Hornes, A. Friters, J. Pot, J. Paleman, and M. Kuiper. 1995. AFLP: A new technique for DNA fingerprinting. Nucleic Acids Res. 23:4407-4414.

Wang, F.R., Z.G. Tong, J.B. Zhao, Z. Zhang, Q. Jiang, J.Y. Guo, Q.H. Chen, K.C. Zhang, and L.J. Jiang. 2008. AFLP analysis of genetic relationship in peach of wild and local varieties germplasm resources. Journal of Fruit Science 3:6.

Wang, L.R., G.R. Zhu, and W.C. Fang. 2006. The evaluation criteria of some botanical quantitative characters of peach genetic resources. Agr. Sci. China 5:905-910.

Wang, X.J., Z.Y. Liu, X.H. Mai, and X.L. Liu. 2010. The use of wild peach germplasms. Gansu Agricultural Science and Technology $2: 2$.

Wang, Y., L.L. Georgi, T.N. Zhebentyayeva, G.L. Reighard, R. Scorza, and A.G. Abbott. 2002. High-throughput targeted SSR marker development in peach (Prunus persica). Genome 45:319-328.

Wang, Y.L. 1984. Peach growing and germplasm in China. International Conference on Peach Growing 173. p. 51-56

Wang, Z. and J. Zhou. 1990. Pollen morphology of peach germplasm. Acta Horticulturae Sinica 17:161-168.

Wu, B., B. Quilot, J. Kervella, M. Génard, and S. Li. 2003. Analysis of genotypic variation of sugar and acid contents in peaches and nectarines through the principle component analysis. Euphytica 132:375-384.

Xu, D., S. Wahyuni, Y. Sato, M. Yamaguchi, H. Tsunematsu, and T. Ban. 2006. Genetic diversity and relationships of Japanese peach (Prunus persica L.) cultivars revealed by AFLP and pedigree tracing. Genet. Resources Crop Evol. 53:883-889.

Yamamoto, T., M. Yamaguchi, and T. Hayashi. 2005. An integrated genetic linkage map of peach by SSR, STS, AFLP and RAPD. J. Jpn. Soc. Hort. Sci. 74:204-213.

Yang, X., K. Zhang, L. Qin, and Y. Wang. 2001. RAPD analysis of germplasm resources on peach. Journal of Fruit Science 18:276-279.

Yu, M.L., R. Ma, J. Xu, Z. Shen, and Z. Zhang. 2004. Identification of genetic relationship of peach species by SSR. Journal of Fruit Science 2:7.

Zhang, F. and Z. Jiang. 2006. Mitochondrial phylogeography and genetic diversity of Tibetan gazelle (Procapra picticaudata): Implications for conservation. Mol. Phylogenet. Evol. 41:313-321.

Zong, X.P. and Y.C. Duan. 1987. The distribution and types of Prunus mira. Chinese Agricultural Technique Press, Beijing, China. 